\title{
On the influence of spatial heterogeneity on an internal boundary layer at a short fetch
}

\author{
B S Murthy ${ }^{1, *}$, R Latha ${ }^{1}$, Cini Sukumaran ${ }^{1}$, A Shivaji ${ }^{2}$ and S Sivaramakrishnan ${ }^{1}$ \\ ${ }^{1}$ Indian Institute of Tropical Meteorology, Dr Homi Bhabha Road, NCL Post, Pune 411 008, India. \\ ${ }^{2}$ National Centre for Antarctic and Ocean Research, Vasco-Da-Gama, Goa, India. \\ *e-mail: murthy@tropmet.res.in
}

\begin{abstract}
Surface layer meteorological data collected at a coastal site, at Vasco-Da-Gama $\left(15^{\circ} 21^{\prime} \mathrm{N}, 73^{\circ} 51^{\prime} \mathrm{E}\right.$, $58.5 \mathrm{~m}$ MSL) (13-18 July, 2002) with prevailing southwesterly surface winds are analyzed to study the characteristics of internal boundary layer at a short fetch using an instrumented tower $(9 \mathrm{~m})$. The spectral and turbulence characteristics of wind are compared with earlier measurements made at a comparatively homogeneous terrain and the standards available in literature. The study show the smaller eddies in the vertical velocity spectrum attains equilibrium with the underlying surface at a short fetch itself and follows spectral similarity. However, this is not followed by longitudinal and transverse velocity spectra under unstable as well as stable conditions.
\end{abstract}

\section{Introduction}

Coastal atmospheric boundary layer (ABL) is inherently heterogeneous, dominated by variations in topography, large temperature gradients and change in surface roughness. Surface heterogeneity leads to different aerodynamic and thermodynamic parameters resulting in significant spatial variability of surface energy fluxes and profiles of variables in the surface layer (Ma et al 2008). The coastal atmospheric surface layer $\left(\sim 0.1 z_{i}, z_{i}\right.$ is the height of $\mathrm{ABL}$ ) is a transition zone under the influence of interactions of dissimilar surfaces and flow adjustments. Estimation of surface fluxes of momentum, heat and water vapour within the transition zone is important for parameterization of fluxes over inhomogeneous terrain as horizontal homogeneity assumption (required for Monin-Obukhov, M-O similarity theory) is not satisfied. Internal boundary layers (IBL) that develop at coastal sites need to be considered while estimating surface fluxes as the fetch is limited to satisfy homogeneity of flow assumption. For surface layer turbulent flux estimation from vertical gradients using $\mathrm{M}-\mathrm{O}$ theory, all measurements are to be made well within the homogeneous layer with sufficient upwind fetch lest it would result in erroneous flux that may not represent the local terrain. The limit up to which the IBL characteristics apply is defined by the depth of IBL; hence it is required to know the IBL height. A thorough review of IBL height formulae and simple models based on IBL concepts which are used for predicting the IBL height within both the neutral and diabatic atmospheric surface layer, given by Savelyev and Taylor (2005), are discussed in context with the IBL height determination at the Goa coast (our field site).

Spectra of turbulence provide useful information on the scales of motion contributing to the production and dissipation of energy, and the turbulent transport of various atmospheric properties. According to Monin-Obukhov similarity theory, the spectra of wind $(u, v, w$ components spectra) when non-dimensionalized with friction velocity, $u_{*}$, reduce to a set of universal curves that are function only of stability, $z / L$ in the homogeneous surface layer, $L$ is Monin-Obukhov (M-O) length, a measure of stability, $z$ is the measurement height (Kaimal and Finnigan 1994). Temperature stratification and static stability depend on

Keywords. Wind spectra; heterogeneity; sea-land interface; IBL. 


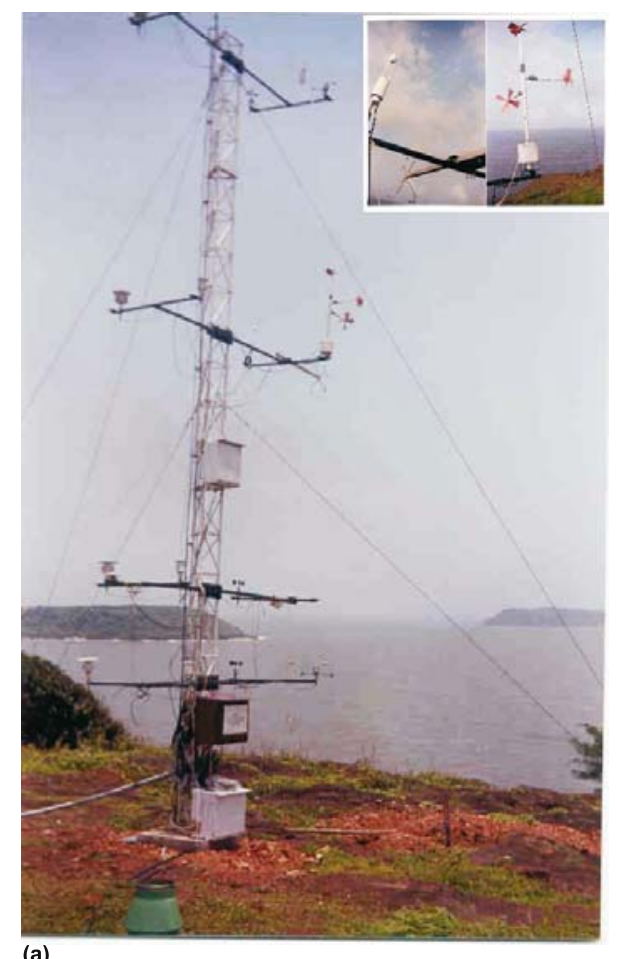

(a)

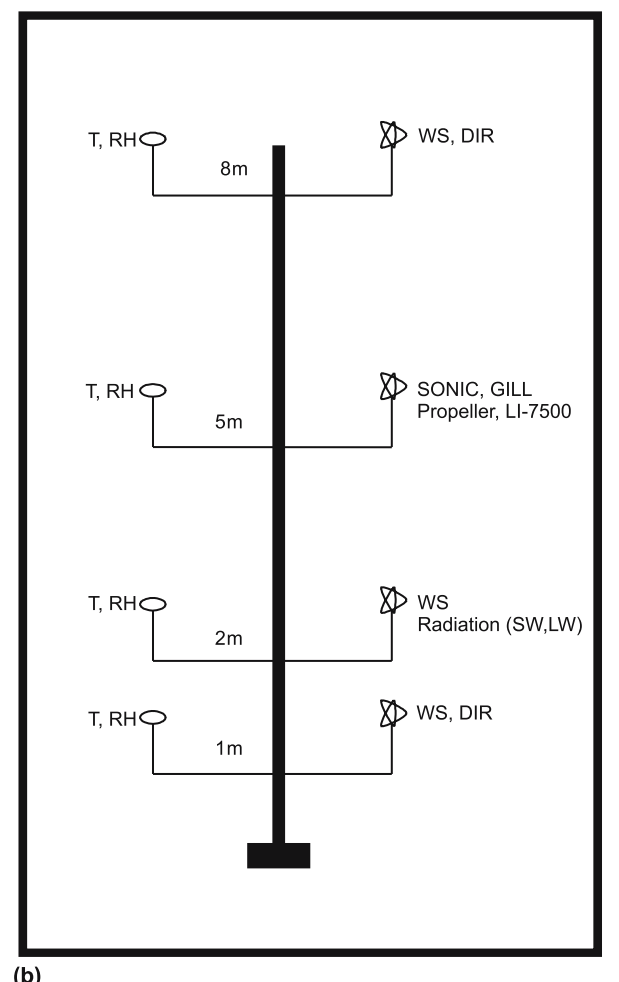

(b)

Figure 1. (a) Micrometeorological tower $(9 \mathrm{~m})$ on the west coast of India at NCAOR, Goa. Inset: LI-7500, Sonic and Gill anemometers at $5 \mathrm{~m}$ above surface ( $\mathrm{L}$ to $\mathrm{R}$ ). (b) Schematic of experimental setup of tower and sensors.

local circulations induced by spatial gradients in temperature and humidity across the coast. Modification of spectral characteristics of wind by the terrain induced circulation by the lee side of the hill has been investigated by Murthy and Dharmaraj (2001). The influence of local circulations like sea breeze manifests in the general spectral characteristics of horizontal wind (Prakash et al 1993).

The present study deals with the turbulence and spectral characteristics of IBL in a complex coastal terrain with a very limited fetch in the upwind direction.

\section{Topography of the site}

The $9 \mathrm{~m}$ high instrumented tower installed by the Indian Institute of Tropical Meteorology (IITM), Pune, in the premises of the National Centre for Antarctic and Ocean Research (NCAOR), VascoDa-Gama $\left(15^{\circ} 21^{\prime} \mathrm{N}, 73^{\circ} 51^{\prime} \mathrm{E}\right)$, Goa is shown in figure 1(a) and figure 1(b) gives the schematic of the actual sensor deployment on the tower. Figure 2(a) shows an approximate sketch of the terrain surrounding the tower (figure 2a), development of IBL (figure $2 \mathrm{~b}$ ) and wind profile over the land surface (figure 2c) when the flow is from sea to land. The tower is $\sim 30 \mathrm{~m}$ away from the Arabian Sea coast and its base height is $\sim 12 \mathrm{~m}$ from the coastal sea surface (figure 2a). The NCAOR buildings are to the north, about $100-150 \mathrm{~m}$ away from the tower. During ARMEX (phase-1) the prevailing surface winds were southwesterly to westerly at Goa. The Arabian Sea is located in the S-W sector relative to the tower. There is a sharp change in surface roughness and surface temperature for the wind from sea to land, hence internal boundary layer develops at the boundary between land and sea with its depth increasing inland. The experimental site has a limited fetch of land in the upwind $\mathrm{S}-\mathrm{W}$ direction. The footprint of the measurement on the tower signifies mostly the maritime air. As shown in figure 2(b), the wind flowing in, gets fully adjusted to the land surface in the layer near to the surface (equilibrium layer) and the wind speed decreases due to the increase in surface roughness. In the layer just above equilibrium layer, the flow is under transition and not fully adjusted with underlying land surface and is called 'transition layer'. Further above the transition layer, the flow is unmodified and is the same as that over upwind sea surface. In neutral conditions, wind speed increases log-linearly in equilibrium layer and then rapidly in transition layer. In the layer of unmodified flow above transition layer wind speed follows log-linear profile. The IBL height is defined as an intersection point of the two log-linear wind profiles; one representing the land surface and the other, sea surface (figure 2c). 


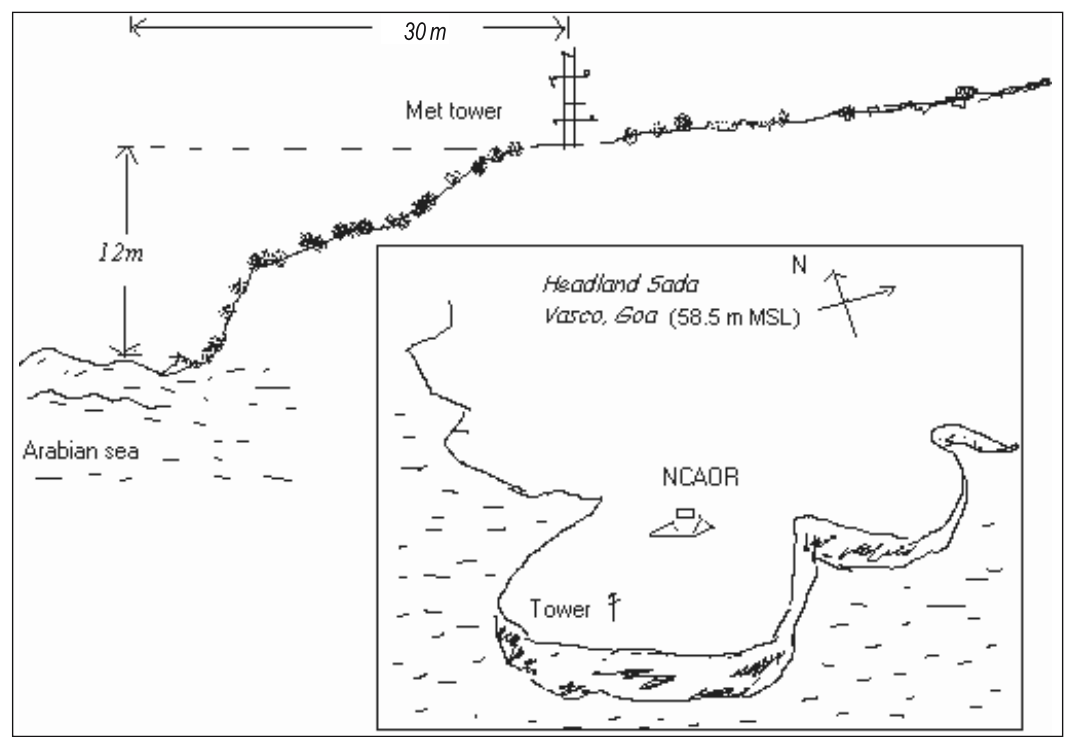

(a)

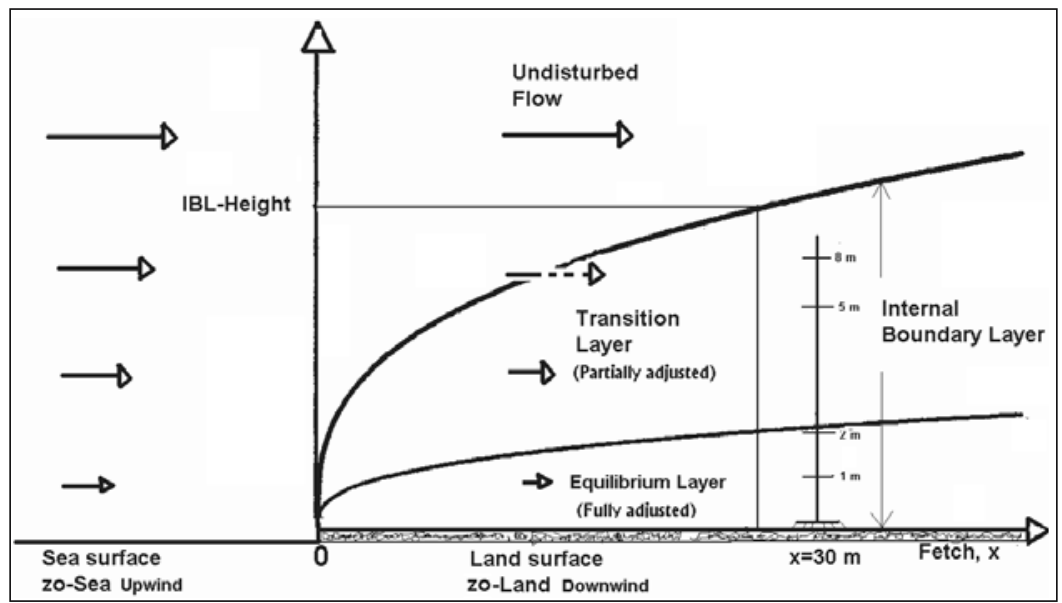

(b)

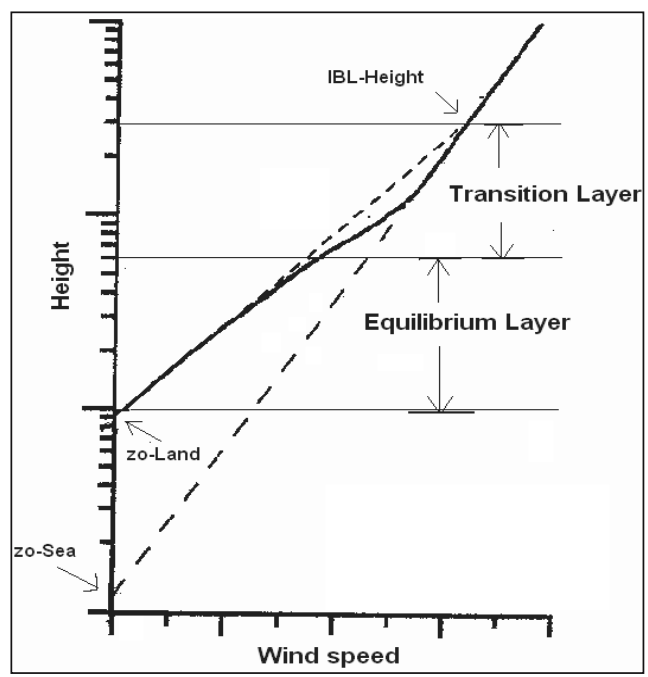

(c)

Figure 2. (a) Schematic of the terrain around the tower, (b) schematic of the development of IBL as wind flows from sea to land illustrating the different layers. $z_{o \text {-land }}, z_{o \text {-sea }}$ represent roughness lengths for land and sea surfaces respectively and (c) schematic of wind profile over land at fetch, $x=30 \mathrm{~m}$. Solid curve is observed wind profile. Dashed lines are extrapolations of linear part of wind profile. $z_{o \text {-land }}$ and $z_{o \text {-sea }}$ indicate roughness lengths for land and sea surfaces respectively. 
Table 1. Sensor specifications.

\begin{tabular}{|c|c|c|c|c|c|}
\hline Parameter & Sensor/instrument & Range & Accuracy & Threshold & $\begin{array}{l}\text { Response time/ } \\
\text { resolution }\end{array}$ \\
\hline Wind speed & 3 cup anemometer & $0-65 \mathrm{~m} \mathrm{~s}^{-1}$ & $\begin{array}{l}0.2 \mathrm{~m} \mathrm{~s}^{-1} \\
\text { up to } 10 \mathrm{~m} \mathrm{~s}^{-1}\end{array}$ & $0.3 \mathrm{~m} \mathrm{~s}^{-1}$ & $8.33 \mathrm{~s}$ \\
\hline Wind direction & $\begin{array}{l}\text { Potentiometric } \\
\text { wind vane }\end{array}$ & $0-357^{\circ}$ & $\pm 3^{\circ}$ & $0.5 \mathrm{~m} \mathrm{~s}^{-1}$ & $1^{\circ}$ \\
\hline Air temperature & $\begin{array}{l}\text { Platinum } \\
\text { resistance } \\
\text { thermometer }\end{array}$ & $-40^{\circ}$ to $60^{\circ} \mathrm{C}$ & $\pm 0.2^{\circ} \mathrm{C}$ & - & $0.1^{\circ} \mathrm{C}$ \\
\hline Relative humidity & $\begin{array}{l}\text { Solid state } \\
\text { capacitance type }\end{array}$ & $0-99 \%$ & $\pm 3 \%$ of $\mathrm{FSR}$ & - & $1 \%$ \\
\hline Solar radiation & $\begin{array}{l}\text { Radiometers } \\
\text { (Eppley) }\end{array}$ & $\begin{array}{l}0.3-3 \mu \mathrm{m} \\
(\mathrm{SW}) \text { and } \\
3-60 \mu \mathrm{m}(\mathrm{LW})\end{array}$ & $\pm 1 \mathrm{Wm}^{-2}$ & - & $22 \mathrm{~s}$ \\
\hline Rainfall & $\begin{array}{l}\text { Tipping bucket } \\
\text { rainguage }\end{array}$ & Unlimited & $+5 \%$ & $0.5 \mathrm{~mm}$ & $0.5 \mathrm{~mm}$ \\
\hline \multicolumn{6}{|c|}{ Sonic anemometer (Applied Technology, USA) } \\
\hline Measurement range & \multicolumn{2}{|c|}{ Wind velocity: $15 \mathrm{~m} \mathrm{~s}^{-1}$} & \multicolumn{3}{|c|}{ Temperature: $-20^{\circ}$ to $+50^{\circ} \mathrm{C}$} \\
\hline Accuracy & \multicolumn{2}{|c|}{$\begin{array}{l}\text { Wind speed: } \pm 0.05 \mathrm{~m} \mathrm{~s}^{-1} \\
\text { Sonic temperature: } \pm 0.05^{\circ} \mathrm{C}\end{array}$} & \multicolumn{2}{|l|}{ Direction: $\pm 0.1^{\circ}$} & \\
\hline Resolution & \multicolumn{2}{|c|}{$\begin{array}{l}\text { Wind speed: } 0.01 \mathrm{~m} \mathrm{~s}^{-1} \\
\text { Temperature: } 0.01^{\circ} \mathrm{C}\end{array}$} & \multicolumn{2}{|l|}{ Wind direction: $0.1^{\circ} \mathrm{C}$} & \\
\hline
\end{tabular}

\section{Experimental setup and data}

The instruments to measure wind speed, direction, air temperature and relative humidity are installed on cross booms fitted on the tower, extending $1.5 \mathrm{~m}$ on each side, at four levels, i.e., 1, 2, 5 and $8 \mathrm{~m}$ (figure 1). Turbulence measurements at a sampling frequency of $10 \mathrm{~Hz}$ are made using sonic anemometer (Applied Technology, USA) and $\mathrm{H}_{2} \mathrm{O} / \mathrm{CO}_{2}$ gas analyzer (Licor-7500, USA) at $5 \mathrm{~m}$ above surface. Eppley radiometers are installed at $2 \mathrm{~m}$ height above the surface that measure solar radiation (short wave-incoming, short wavereflected, long wave-incoming, long wave-outgoing) and a Gill propeller anemometer mounted at $5 \mathrm{~m}$ height measures the three wind components. The data from the slow instruments, viz., wind speed (cup anemometer), direction (vane), air temperature (PT1000), humidity (Humicap), rain fall (tipping bucket), atmospheric pressure (barometer) and radiation (radiometers), are logged into a data logger, mounted at the foot of the tower. The data from sonic anemometer, infrared hygrometer and Gill anemometer are stored in a PC-based data logger in the laboratory near the tower. Various details on the range, accuracy of the measured parameters, threshold limits and sensor response time/resolution are tabulated in table 1. Slow response sensors are sampled at
$1 \mathrm{~Hz}$ and 1 minute mean values are logged. Digital data at $10 \mathrm{~Hz}$ sampling frequency from sonic anemometer and $\mathrm{H}_{2} \mathrm{O} / \mathrm{CO}_{2}$ gas analyzer are logged in a $\mathrm{PC}$.

Cup anemometers and Gill propeller anemometer are calibrated in wind tunnel at India Meteorological Department (IMD), Pune. Temperature sensors are calibrated using water bath thermostat and humidity sensors using standard chemicals in the laboratory at IITM. Profiles of 30 minutes-mean wind and temperature are used; 48 profiles in a day and for 15 days, to study the characteristics of IBL very close to the sea coast. Surface fluxes of momentum and sensible heat (including the contribution from moisture; buoyancy flux) are estimated from the turbulence observations (30 minutes duration) by sonic anemometer.

The background meteorological conditions at the station at the time of campaign may be summarized as follows. The period of analysis, July 2002 has been one of the driest months (Hatwar 2005) on record with a regional deficiency of $59 \%$ monsoon rainfall as per India Meteorological Department. Rainfall measured at the field site for July is $272 \mathrm{~mm}$ with only two significant rainfall events of 74 and $91 \mathrm{~mm}$. An anti-cyclonic circulation was noticed off the west coast of India. The frequency distribution of wind direction at $5 \mathrm{~m}$ above surface 

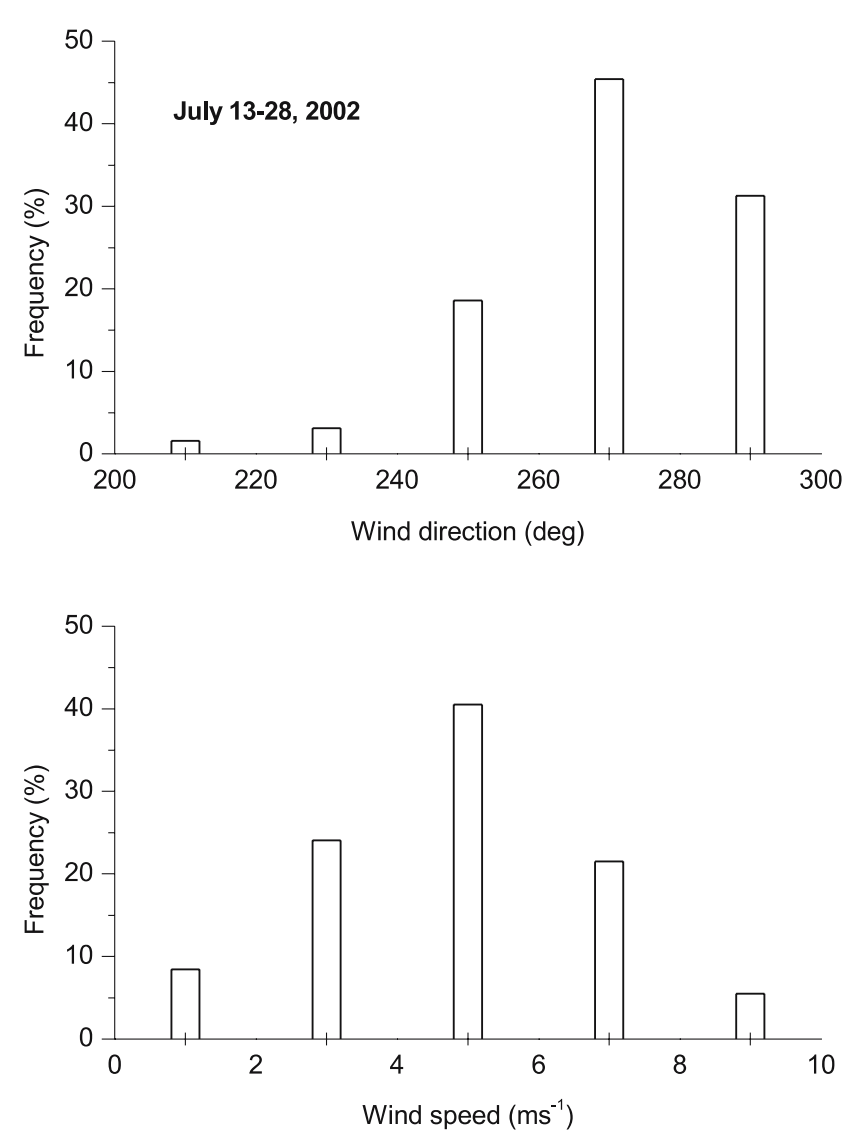

Figure 3. Wind direction and speed during July 13-28, 2002.

(from sonic anemometer) showed that $45 \%$ of the time during the period 13-28 July 2002, wind blew from $260-280^{\circ}$, i.e., WSW-WNW (figure 3 ) with wind speed $4-6 \mathrm{~m} \mathrm{~s}^{-1}$.

\section{Results and discussion}

\subsection{IBL height determination at the station}

Parameterization of fluxes by $\mathrm{M}-\mathrm{O}$ similarity theory assumes homogeneity of terrain. When the terrain is heterogeneous such as sea coast, the wind flow undergoes transition according to the underlying surface and an internal boundary layer starts developing at the interface of the two dissimilar surfaces. The depth of this IBL increases with fetch and its turbulent characteristics are different from the conventional ABL. It is important to find its depth to know the location of sensors within this layer. Therefore, we attempted to estimate the height of the IBL present here with the available formulae and observations. Moreover, as the wind spectra obtained from sonic anemometer are studied, we have to know in which layer the measurements are made.
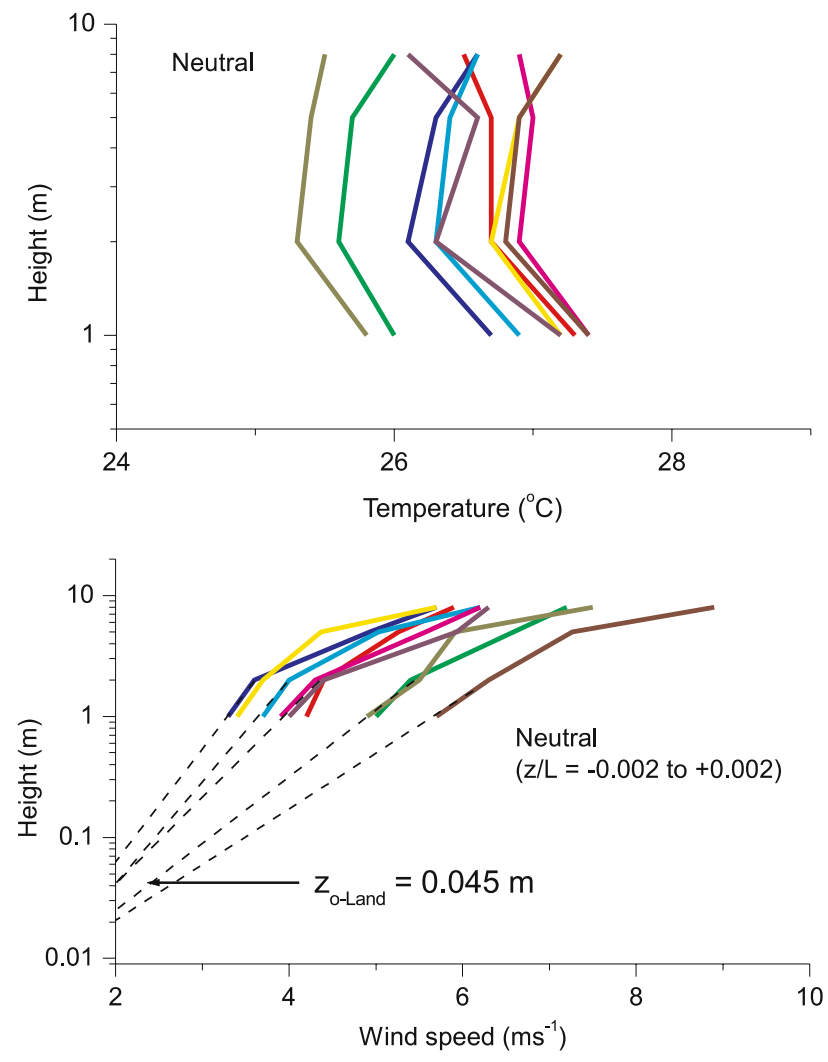

Figure 4. Profiles of temperature and wind for neutral stability conditions. Stability, $z / L$ is between -0.002 and +0.002 , indicating neutral condition. Dashed lines intercept give land surface (downwind) roughness lengths in the range $0.02-0.07 \mathrm{~m}$. Mean roughness length, $z_{o D}=0.045 \mathrm{~m}$.

\subsubsection{Estimation of IBL height using the formulae}

Wind speed profiles within and above the IBL are required for determining the near-neutral loglinear wind profile (figure 2c) that represent land (downwind) and sea (upwind) surfaces (Savelyev and Taylor 2005). Their extrapolated intersection point marks the depth of IBL as in figure 2(c). Profiles of horizontal wind and temperature for neutral stability with prevailing winds of $4-6 \mathrm{~m} \mathrm{~s}^{-1}$ (at $8 \mathrm{~m}$ above surface) are shown in figure 4 for the period July 13-28, 2002. In this dataset, we have winds at $1,2,5$ and $8 \mathrm{~m}$ with an inflection point observed at $2 \mathrm{~m}$ separating the equilibrium layer and transition layer. Winds are relatively high at 5 and $8 \mathrm{~m}$, apparently falling in the transition layer of IBL. Unfortunately, measurements are not available above $8 \mathrm{~m}$ to confirm the log-linear wind profile representing the unmodified flow over the coastal sea. Thus to fix the top of the transition layer (i.e., IBL height) winds at higher levels till the undisturbed flow are required.

The land surface roughness length, $z_{o \text {-land }}$ $\left(=z_{o D}\right)$ can be obtained by extrapolating the wind profile in the equilibrium layer (up to 
Table 2. IBL heights obtained from various formulae for neutral stability.

\begin{tabular}{|c|c|c|c|}
\hline Formula & Reference & IBL height $(\mathrm{m})$ & Remarks \\
\hline$\delta / z_{o D}=10.56\left(x / z_{o D}\right)^{0.33}$ & Cheng and Castro (2002) & $\delta=4.06$ & $\begin{array}{l}z_{o D}=0.045 \mathrm{~m} \text {, obtained } \\
\text { from log wind profiles in } \\
\text { equilibrium layer, up to } 2 \mathrm{~m}\end{array}$ \\
\hline$\delta / z_{\text {or }}=0.28\left(x / z_{\text {or }}\right)^{0.8}$ & Wood (1982) & $\delta=2.29$ & $z_{o r}=\max \left(z_{o D}, z_{o U}\right)$ \\
\hline$\delta=0.09 x^{0.8}$ & Jegede and Foken (1999) & $\delta=1.37$ & For $x=140$ to $260 \mathrm{~m}$ \\
\hline$\delta=0.2 x^{0.78-0.32 z / L}$ & Bergstrom et al (1988) & $\delta=2.84$ & $\begin{array}{l}z / L=-0.001 \\
(\text { from sonic anemometer) }\end{array}$ \\
\hline Wind profile & Observations at Goa & $\delta>8$ & $\begin{array}{l}\text { Wind profile up to undis- } \\
\text { turbed flow is necessary for } \\
\text { accurate determination of } \delta\end{array}$ \\
\hline
\end{tabular}

$x=$ fetch $(\mathrm{m}), z_{o D}=$ downwind (land) roughness length $(\mathrm{m}), z_{o U}=$ upwind (sea) roughness length, $z_{o r}=$ maximum of $z_{o D}$ and $z_{o U}, z$ height of measurement $(\mathrm{m}), L=$ Monin-Obukhov length $(\mathrm{m})$.

$2 \mathrm{~m})$. As shown in figure $4, z_{o \text {-land }}$ varies from 0.02 to $0.07 \mathrm{~m}$ for neutral stability $(z / L=-0.002$ to +0.002$)$. Monin-Obukhov length, $L$ is calculated as:

$$
L=\frac{-u_{*}^{3}}{\left(k\left(g / T_{v}\right) \overline{w^{\prime} T^{\prime} v}\right)},
$$

where $k=0.4$, Von-Korman constant and all other parameters $\left(u_{*}\right.$, the friction velocity and $T_{v}$, the virtual temperature) except ' $g$ ' obtained form sonic anemometer. The mean roughness length $\left(z_{o D}=0.045 \mathrm{~m}\right)$ has been used in the equation (Panofsky et al 1982),

$$
\frac{\delta}{z_{o D}}=a_{\mathrm{IBL}}\left(\frac{x}{z_{o D}}\right) b_{\mathrm{IBL}}
$$

$z_{o D}$ is downwind (land) roughness length to estimate the IBL height for different stability conditions. The IBL height $(\delta)$ is found to be $0.62,4.09$ and $12.53 \mathrm{~m}$ respectively for stable $\left(a_{\mathrm{IBL}}=0.2, b_{\mathrm{IBL}}=0.65\right)$, neutral $\left(a_{\mathrm{IBL}}=0.5\right.$, $\left.b_{\mathrm{IBL}}=0.8\right)$ and unstable $\left(a_{\mathrm{IBL}}=0.8, b_{\mathrm{IBL}}=0.9\right)$ conditions. IBL heights are also estimated using various formulae available in literature applicable for short fetch (table 2). For neutral conditions $(-0.002<z / L<+0.002)$ IBL heights estimated from the formulae vary from 1.37 to $4.06 \mathrm{~m}$. The wind profiles at this site indicate the IBL height at a fetch of $30 \mathrm{~m}$ to be at least $8 \mathrm{~m}$ (table 2). The complexity in existing conditions at the site, viz., change in temperature, change in surface roughness, change in slope and the very short fetch, are not taken care of altogether in any of the existing formulae and hence they fail to arrive at the proper
IBL height. It may well be concluded that for accurate determination of IBL height over a complex coastal site with very short fetch when significant spatial gradients in surface roughness, temperature and slope existing together, can only be determined from wind and temperature profiles up to sufficient height and not by the currently available empirical formulae for IBL height in literature.

\subsection{Spectra of wind}

Since the sonic anemometer is well within the IBL, we have decided to study the spectral characteristics of this layer. Shao et al (1991) examined the similarity of turbulence within the TIBL (Thermal Internal Boundary Layer) and the effectiveness of local scaling for inhomogeneous conditions. It is suggested that, even in advective conditions, turbulence can be considered as being in local equilibrium. Our interest here is to study how far the spectra of wind follow similarity laws at a coastal site with complex terrain. The time series data for 30 minutes is processed to remove means, trends in the signal and then cosine tapered before subjecting it to Fast Fourier Transform (FFT) analysis following Stull (1988). Since the terrain is uneven and sloping, three dimensional co-ordinate rotation is performed to ensure mean transverse $(v)$ and vertical $(w)$ wind to be zero and to minimize the error in flux estimates. The first rotation makes mean- $v$ zero and the second one mean- $w$. This procedure was established by independently checking the heat fluxes and heat flux balance calculation (Kaimal and Finnigan 1994). The raw spectrum is block averaged to smoothen the spectrum with more number of points averaged for higher frequencies. Such smoothed spectra of wind $(u, v$ and $w)$, normalized by $u_{*}^{2} \varphi_{\varepsilon}^{2 / 3}$ are shown in figure 5 for a range of atmospheric stability $(-0.838<z / L<0.926)$ 


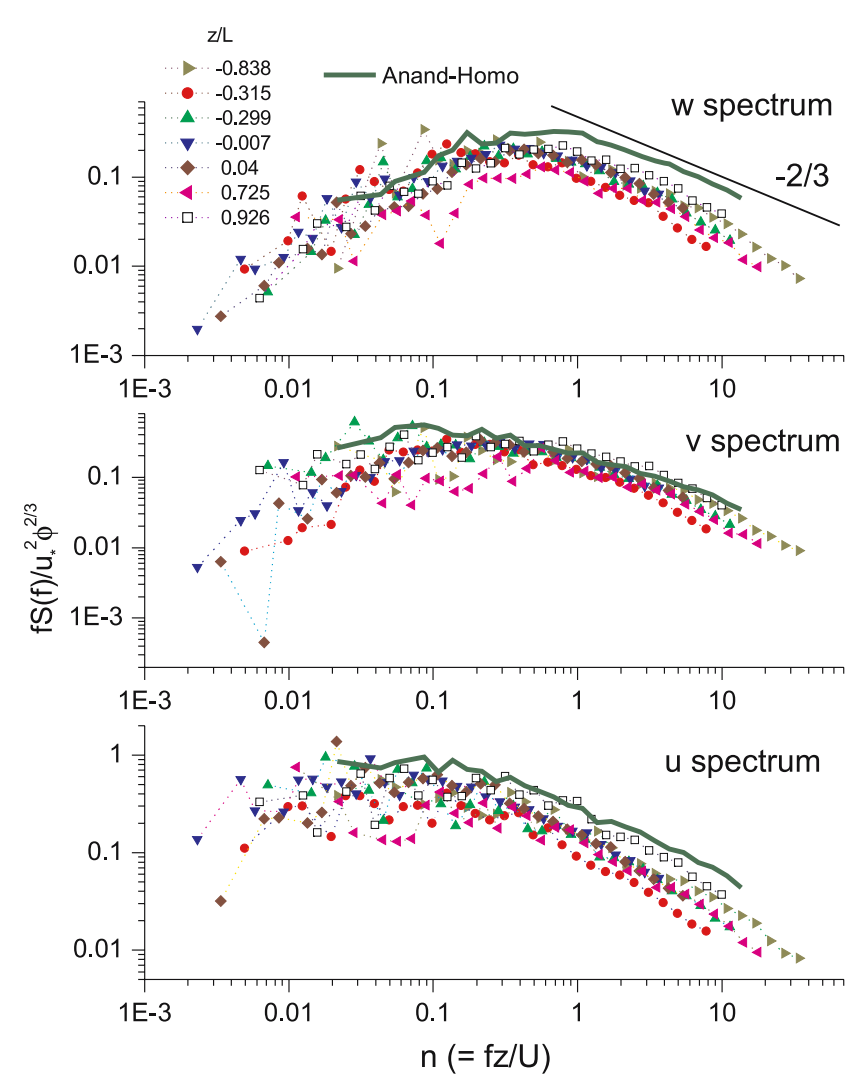

Figure 5. Normalized spectra of longitude $(u)$, transverse $(v)$ and vertical $(w)$ wind components as a function of non-dimensional frequency $n(=f z / U)$ for various stability $(z / L)$ conditions. $U$ is mean horizontal wind. Line indicates inertial sub-range with $-2 / 3$ slope. Solid curve is the mean spectrum for neutral stability at Anand, a comparatively homogeneous terrain.

conditions, $f$ is frequency and $S(f)$ is spectral density at $f$ and

$$
\begin{aligned}
\varphi_{\varepsilon}^{2 / 3} & =\left(1+0.5 ! z / L !^{2 / 3}\right)^{3 / 2}, & & -2 \leq z / L \leq 0 \\
& =(1+5 z / L), & & 0 \leq z / L \leq 1
\end{aligned}
$$

$\varphi_{\varepsilon}^{2 / 3}$ is the non-dimensional turbulence energy dissipation function (Kaimal and Finnigan 1994).

A reference spectrum for neutral stability over homogeneous terrain (Anand, Gujarat) is shown for comparison (figure 5). Characteristic slope of $-2 / 3$ in the inertial sub-range is seen in the spectra of all the three wind components. Inertial subrange is characterized by minimum energy dissipation, isotropy and gradual cascading of energy from large eddies to small eddies. It is noticeable that the spectral energy at Anand for neutral condition is even higher than Goa for unstable conditions. Gradual shift in the peaks with increase in stability for stable $(z / L+\mathrm{ve})$ conditions is observed for

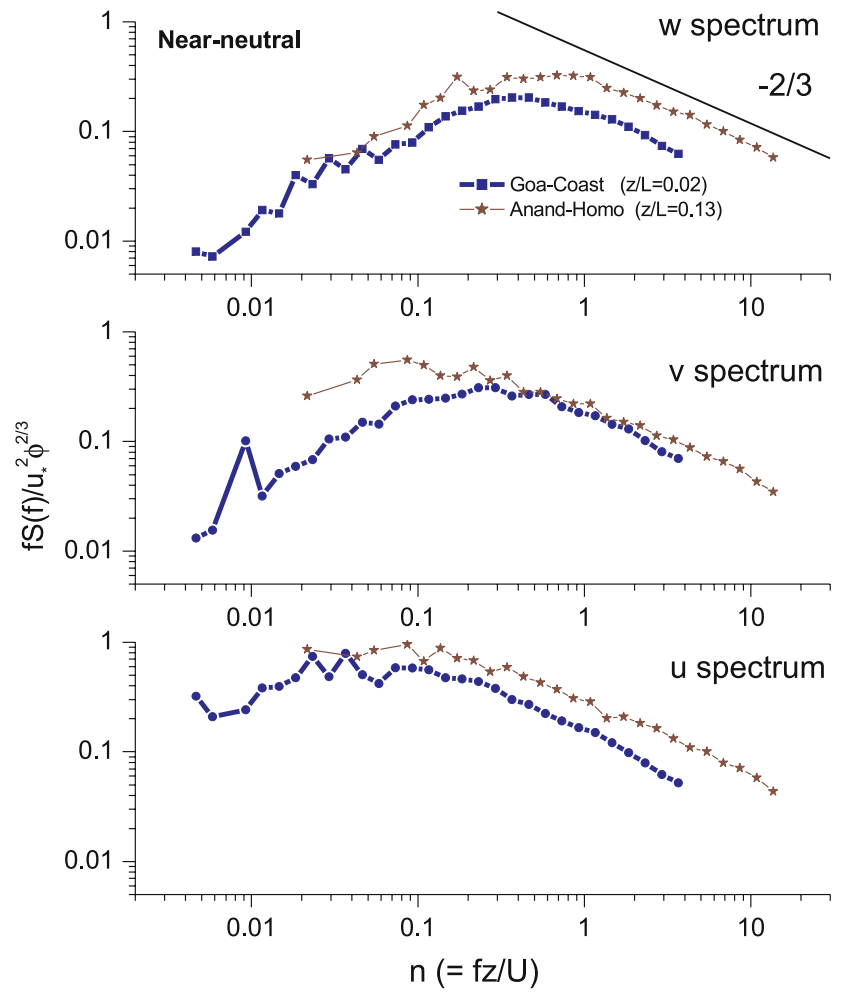

Figure 6. Mean near-neutral spectra of $u, v$ and $w$ for Goa and Anand.

$w$ spectra. Elaborating on figure 5, figure 6 compares the spectral characteristics of $u, v$ and $w$ of Goa (heterogeneous) and Anand (comparatively homogeneous) for near-neutral conditions. Evidently the spectral energy at Goa $(z / L=0.02)$ for all the wind components is lesser than Anand $(z / L=0.13)$ with higher stability. This might be the result of the presence of IBL at Goa. However, the spread to the lower frequency is more extended in Goa possibly due to the higher prevailing wind speeds $\left(4-6 \mathrm{~m} \mathrm{~s}^{-1}\right)$ than Anand $\left(<1 \mathrm{~m} \mathrm{~s}^{-1}\right)$. The peak frequency of $u$-spectrum for Goa (0.037), lower than for Anand (0.086) indicates the presence of relatively large eddies at Goa.

Local heterogeneity of the flow could increase the turbulence intensity in the vertical wind $\left(\sigma_{w}\right)$ relative to that over a more homogeneous terrain, simultaneously causing a reduction in turbulence in the horizontal $\left(\sigma_{u}\right)$. A comparison of turbulence statistics is given in table 3 that compares a heterogeneous (Goa) to a relatively homogeneous (Anand) and the referred (Kansas experiment) homogeneous (Stull 2000) terrain; the ratio $\left(\sigma_{w} / \sigma_{u}\right)$ is increasing as the heterogeneity increases, with a maximum (0.71) at Goa.

Figure $7(\mathrm{a})$ shows $w$-spectrum plotted against non-dimensional frequency, $n(=f z / U)$ for unstable, near-neutral and stable conditions that shows clearly the gradual shift in the frequency 
Table 3. Comparison of turbulence statistics.

\begin{tabular}{lccc}
\hline Parameter & Goa & Anand & $\begin{array}{c}\text { Stull (2000) } \\
\text { (page 83) }\end{array}$ \\
\hline$\sigma_{w} / u_{*}$ & 1.27 & 1.50 & 1.25 \\
$\sigma_{u} / u_{*}$ & 1.80 & 2.40 & 2.50 \\
$\sigma_{v} / u_{*}$ & 2.00 & 2.45 & 1.60 \\
$\sigma_{w} / \sigma_{u}$ & 0.71 & 0.63 & 0.50 \\
\hline
\end{tabular}
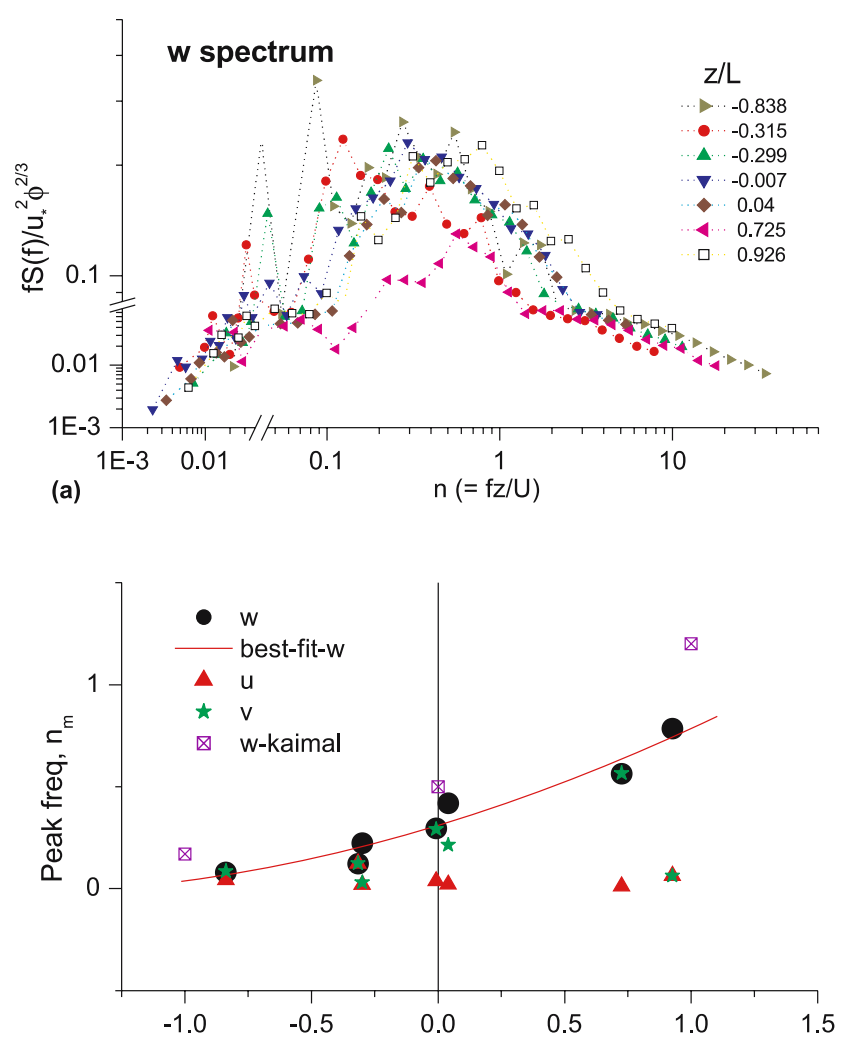

(b) $\mathrm{Z} / \mathrm{L}$

Figure 7. (a) $w$-spectra for $z / L$ in the range -0.838 to +0.926 . Axes breaks and scale change may be noted. (b) Peak-frequencies $\left(n_{m}\right)$ for $u, v$ and $w$ spectra as a function of stability, $z / L$. Kaimal's data points for $w$-spectrum are also included for reference.

corresponding to maximum energy as $z / L$ changes from unstable to stable (negative to positive values) conditions. Breaks in the axes are meant to illustrate clearly the shift in energy peaks and the corresponding frequencies. Spectral energy also falls as stability increases. Figure $7(\mathrm{~b})$ shows the variation of non-dimensional frequency maximum, $n_{m}(=f z / U)$ with $z / L$ for $w, u$ and $v$-spectra. $n_{m}$ for $w$-component $\left(n_{m}-w\right)$ increases rapidly with $z / L$ on stable conditions. As instability increases $(-z / L), n_{m}-w$ decreases. Peak frequencies of $w$-spectrum at Goa at all $z / L$ values fall below that of Kaimal's data points (figure $7 \mathrm{~b}$ ). The orderly shift in $w$-spectrum with $z / L$ confirms that $\mathrm{M}-\mathrm{O}$ similarity laws are well followed by vertical velocity $(w)$ at this coastal site. Spectral peaks $\left(n_{m}\right)$ for $u$ and $v$ spectra do not show any systematic variation with instability $(-z / L)$ as expected due to the influence of larger mesoscale eddies on the surface layer turbulence.

In stable conditions, over a homogeneous terrain, $u$ and $v$ spectra (Kaimal's data not included in figure $7 \mathrm{~b}$ ) follow $\mathrm{M}-\mathrm{O}$ scaling (Kaimal and Finnigan 1994), but in the IBL at Goa, they are not observed to be shifting to higher frequencies as $z / L$ increases. This may be due to the large eddies in $u$ and $v$ spectra having long memory that take longer fetch to come in equilibrium with the new surface.

Variation of peak-frequency, $n_{m}$ with $z / L$ is given in table 4 along with $u_{*}$ and buoyancy flux

$$
H=\rho C_{P} \overline{w^{\prime} T^{\prime} v}
$$

estimated by eddy-correlation technique where $w^{\prime}$ is vertical velocity fluctuation, $T^{\prime} v$, virtual air temperature fluctuation, $C_{P}$, specific heat at constant pressure and $\rho$, air density. $T^{\prime} v$ and $w^{\prime}$ are obtained from sonic anemometer measurements of three wind components $(u, v, w)$ and virtual temperature. Sensible heat flux is also estimated (results not shown) with simplified profile method (Bolle and Streckenbach 1993) to ensure the layer properties exists, viz., equilibrium (1-2m) and transition $(2-8 \mathrm{~m})$. Friction velocity, $u_{*}$ values are of the same order while there is gross mismatch in sensible heat flux calculated by profile method in $1-2 \mathrm{~m}$ and those obtained by sonic anemometer at $5 \mathrm{~m}$, whereas the values for layer $2-8 \mathrm{~m}$ are comparable.

According to Panofsky et al (1982) small eddies in the upstream flow attain equilibrium with the new surface at a small fetch itself whereas the large eddies, with long memory, get partially adjusted. Over the coastal site here, small-scale turbulence seems to be not so sensitive to spatial heterogeneity whereas profiles of mean wind and temperature show multiple inflection points. This may be due to the rapid adjustment of small eddies with the underlying surface that results in $w$-spectrum following $\mathrm{M}-\mathrm{O}$ similarity laws. Large eddies contained in the wind flow over sea will have to travel a few kilometers inland to attain equilibrium with the land surface due to their long memory. Hence $u$ and $v$ spectra (involving large eddies) at a short fetch from the coast are not observed to scale with stability under stable $(+z / L)$ conditions (figure $7 \mathrm{~b}$ ) unlike over a homogeneous terrain. Al-Jiboori et al (2004) studied power spectra of longitudinal and vertical components of wind velocity over a variety of terrain types: uniform, inhomogeneous and 
Table 4. Variation of $n_{m}, u_{*}$, and buoyancy flux, $H$ with stability, $z / L$.

\begin{tabular}{|c|c|c|c|c|c|c|}
\hline \multirow[b]{2}{*}{$z / L$} & \multicolumn{2}{|c|}{ Peak-frequency, $n_{m}$ for $w$-spectrum } & \multirow[b]{2}{*}{$\begin{array}{c}u_{*} \\
\left(\mathrm{~m} \mathrm{~s}^{-1}\right)\end{array}$} & \multirow{2}{*}{$\begin{array}{l}\text { Buoyancy } \\
\text { flux, H } \\
\left(\mathrm{Wm}^{-2}\right)\end{array}$} & \multirow[b]{2}{*}{$\begin{array}{l}\text { Virtual air } \\
\text { temp }\left({ }^{\circ} \mathrm{C}\right)\end{array}$} & \multirow{2}{*}{$\begin{array}{c}\text { Mean } \\
\text { horizontal } \\
\text { wind, } U\left(\mathrm{~m} \mathrm{~s}^{-1}\right)\end{array}$} \\
\hline & $\begin{array}{c}\text { Coastal site } \\
\text { (Goa) }\end{array}$ & $\begin{array}{c}\text { Kansas expt. } \\
\text { (Kaimal 1982) }\end{array}$ & & & & \\
\hline-1.0 & 0.05 & 0.17 & - & - & - & - \\
\hline-0.838 & 0.08 & & 0.14 & 42 & 25.1 & 0.6 \\
\hline-0.315 & 0.12 & & 0.22 & 59 & 25.9 & 2.7 \\
\hline-0.299 & 0.22 & & 0.21 & 48 & 25.8 & 1.9 \\
\hline-0.007 & 0.29 & & 0.43 & 10 & 24.9 & 5.8 \\
\hline 0.00 & 0.35 & 0.5 & & - & & - \\
\hline 0.04 & 0.42 & & 0.31 & -21 & 26.0 & 3.9 \\
\hline 0.725 & 0.56 & & 0.07 & -4 & 24.3 & 1.2 \\
\hline 0.926 & 0.78 & & 0.06 & -4 & 23.8 & 2.1 \\
\hline 1.0 & 0.84 & 1.2 & - & - & - & - \\
\hline
\end{tabular}

urban. Their results show that the spectral shapes and peaks of $u$-spectra are sensitive to local terrain, while those of $w$-spectra are not affected by changes in roughness surface. Their results support our findings.

\section{Conclusions}

Conclusions of the above study may be summarized as:

- There exists an equilibrium layer extending up to $\sim 2 \mathrm{~m}$ above surface at $30 \mathrm{~m}$ from the coast for prevailing south-westerly winds of $4-6 \mathrm{~m} \mathrm{~s}^{-1}$. The layer between 2 and $8 \mathrm{~m}$ seems to represent transition region with a relatively sharp increase in wind speed.

- The IBL formulae in literature are found to be inadequate to estimate the IBL height due to terrain complexity such as change in temperature, surface roughness and slope in addition to very short fetch present due to their inherent limitations in assumptions. Wind profiles of upwind and downwind up to the height of undisturbed flow are necessary to determine IBL height.

- Ratio of standard deviation of $w$ and $u, \sigma_{w} / \sigma_{u}$ is 0.71 at Goa and 0.63 at Anand indicating an increase with increase in heterogeneity of the upwind terrain.

- Heterogeneity of the terrain appears to have little effect on vertical velocity spectrum as the peak frequency shifts systematically with stability, since small eddies in the flow adjust rapidly and come in equilibrium with the underlying surface.

- Peak frequencies in $u$ and $v$ spectra in the transition layer of IBL do not shift systematically under stable conditions as over a homogeneous terrain. This might be due to the large eddies with long memory that adjust only partially with the surface at a short fetch.

\section{Acknowledgements}

The authors undoubtedly thank the unknown reviewers for their constructive guidance that has helped a long way in improving the manuscript. The authors would like to thank the Department of Science \& Technology (DST), Government of India for funding this project. We extend our thanks to the Director, IITM and the Director, NCAOR, Goa, for extending the infrastructure facilities. We thank Dr Bhaskar Rao, NCAOR for the kind co-operation during the field campaign. We are also thankful to IMD, Pune for extending their instrument calibration facility.

\section{References}

Al-Jiboori M H, Xu Y and Qian Y 2004 Velocity spectra over different terrains; Atmos. Sci. Lett. 2 32-38.

Bergstrom H, Johansson P E and Smedman A S 1988 A study of wind speed modification and internal boundary layer heights in a coastal region; Bound.-Layer Meteorol. 42 313-335.

Bolle H J and Streckenbach B 1993 The Echival Field Experiment in Desertification-Threatened Area (EFEDA), Final report, Free University of Berlin, Germany.

Cheng H and Castro I P 2002 Near wall flow development after a step change in surface roughness; Bound.-Layer Meteorol. 105 411-432.

Hatwar H R, Jenamani R K and Kalsi S R 2005 Mausam Special issue on ARMEX $\mathbf{5 6}$ 7-18.

Jegede O O and Foken Th 1999 A study of internal boundary layer due to a roughness change in neutral conditions observed during LINEX field campaigns.

Kaimal J C and Finnigan J J 1994 Atmospheric Boundary Layer Flows (New York: Oxford University Press) 289 pp.

Ma Y, Menenti M, Feddes R and Wang J 2008 Analysis of the land surface heterogeneity and its impact on 
atmospheric variables and the aerodynamic and thermodynamic roughness lengths; J. Geophys. Res. 113 doi: 10.1029/2007JD009124.

Murthy B S and Dharmaraj T 2001 Characteristics of turbulence in the atmospheric surface layer over a complex terrain; Ind. J. Radio \& Space Phys. 30 260-265.

Murthy B S and Sivaramakrishnan S 2006 Moist convective instability over the Arabian Sea during the Asian summer monsoon 2002; Meteorol. Appl. 13 63-72.

Panofsky H A, Larko D, Lipschutz R, Stone G, Bradley E F, Bowen A J and Hojstrup J 1982 Spectra of velocity components over complex terrain; Quart. J. Roy. Meteorol. Soc. 108 215-230.

Prakash J W J, Radhika R, Nair K N, Gupta K S and Kunhikrishnan P K 1993 On the spectral behaviour of atmospheric boundary-layer parameters at Thumba, India; Quart. J. Roy. Meteorol. Soc. 119 187-197.

Savelyev S A and Taylor P A 2005 Internal Boundary Layers: I height formulae for neutral and diabatic flows; Bound.-Lay. Meteorol. 115 1-25 and the references therein.

Shao Y J, Hacker M and Schwerdtfeger P 1991 The structure of turbulence in a coastal atmospheric boundary layer; Quart. J. Roy. Meteorol. Soc. 117 1299-1324.

Stull R B 1988 An introduction to boundary layer meteorology (Dordrecht: Kulwer Academic Publications).

Stull R B 2000 Meteorology for Engineers and Scientists (USA: Brooks/Cole) $83 \mathrm{pp}$.

Wood D H 1982 Internal boundary layer growth following a change in surface roughness; Bound.-Layer Meteorol. 22 241-244. 